\title{
Models to support cropping plan and crop rotation decisions. A review
}

\author{
Jérôme Dury • Noémie Schaller · Frédérick Garcia • \\ Arnaud Reynaud $\cdot$ Jacques Eric Bergez
}

Accepted: 13 January 2011 / Published online: 8 July 2011

(C) INRA and Springer Science+Business Media B.V. 2011

\begin{abstract}
Farmers must yearly allocate fields to different crops and choose crop management options. Far from being obvious, these decisions are critical because they modify farm productivity and profitability in the short and long run. To support farmers and efficiently allocate scarce resources, decision support models are developed. Decision support models are mainly based on two concepts, the cropping plan and the crop rotation decisions. These decisions concern crop choice, crop spatial distribution within the farmland and crop temporal successions over years. Decisions are at the core of the farm management. Decisions have strong impacts on resource use efficiency and on environmental processes at both farm and landscape scales. We review here more than 120 references where cropping plan and crop rotation decision concepts were incorporated into models. Our aim is to review how these two concepts have been formalised and used in agronomic, economic and land-use studies. We found that
\end{abstract}

\author{
J. Dury $(\bowtie) \cdot J$. E. Bergez \\ INRA, UMR 1248 AGIR, \\ 31326 Castanet-Tolosan, France \\ e-mail: Jerome.Dury@toulouse.inra.fr \\ N. Schaller \\ AgroParisTech, UMR 1048 SADAPT, \\ 75005 Paris, France \\ F. Garcia \\ INRA, UMR BIA, \\ 31326 Castanet-Tolosan, France
}

A. Reynaud

TSE(LERNA-INRA), Université de Toulouse 1,

Manufacture des Tabacs - Bât.F, 21 allée de Brienne,

31042 Toulouse, France

J. Dury $\cdot$ A. Reynaud $\cdot$ J. E. Bergez

UMTeau, Arvalis/Cetiom/INRA,

31450 Baziège, France cropping plan decisions selection and design have been done using many approaches based on different objectives and handled at very different scales. The main results show that (1) cropping plan design decisions have mainly been tackled as a static concept, i.e. as if they were a single decision made only once a year or once a rotation; (2) modelling the achievement of a suitable cropping plan is often based on a single monetary criterion optimization procedure instead of a multi-criteria assessment; and (3) when considered, uncertainty of information is defined as stochastic factors or probability of occurrence, but this probability is kept static whatever the knowledge of the dynamic evolution of various constraints. We argue that cropping plan and crop rotation decisions are on the contrary dynamic processes incorporated into a succession of other planned and adaptive decisions made at annual and long-term horizons. For supporting farmers in their decisions, new cropping plan decision models will require new modelling paradigm. A promising improvement could be reached by including explicitly the simulation of the farmers' decision-making processes, based on the simulation of the decision-making processes rather than on single normative approaches.

Keywords Cropping systems · Decision-making · Modelling $\cdot$ Decision-aid

\section{Contents}

1. Introduction................................................................. 3

2. Terminology, definitions and concepts........................4

2.1. Cropping plan.............................................. 4

2.2. Crop rotation................................................... 5

2.3. Cropping plan decisions................................. 5

3. Why and how cropping plan selection have been modelled. .6 
3.1. Model-based exploration.................................6

3.1.1. Problem formalisation................................6

3.1.2. Problem resolution................................... 9

3.2. Policy and land-use assessments.......................11

3.2.1. Policy assessment....................................11

3.2.2. Landscape ecology..................................12

4. Discussion.......................................................... 14

4.1. Cropping plan decision-making as a dynamic process.

4.2. Uncertainty and risk management.....................14

4.3. Spatial representation and scale issues...............15

5. Conclusion. 16

\section{Introduction}

Agriculture, being the main type of land-use in Europe, accounting for $45 \%$ of European land cover (Rounsevell et al. 2003), is being increasingly questioned on the environmental side effects of its activities. Water use, soil erosion, biodiversity and landscape design are some of the issues that agriculture now has to deal with; rural employment and energy production also have to be accounted for without compromising the primary objective of agriculture, which is food production (Millennium Ecosystem Assessment 2005). Adding to these concerns, the expected climate change (Pachauri and Reisinger 2007), market variation and regulation changes for more sustainable resource management compel farmers to continuously adapt their practices. These new practices should address the challenges related to the environment, resource use efficiency and the economic sustainability of farms simultaneously (Meynard et al. 2001). As chemical inputs are increasingly forbidden (European Parliament Council 2006), the use of more agroecological concepts is required not only in farm production processes but also during the design phase of innovative cropping systems (Griffon 1999; Dalgaard et al. 2003). The renewed popularity of crop rotation as a key concept for designing cropping systems is an illustration of such changes (e.g. Vereijken 1997; Dogliotti et al. 2004; Sadok et al. 2009). The adoption of innovative cropping systems is a challenging goal for the agricultural sector and lead researchers to requestion the methods and concepts on which the developments of these innovative systems are based. "It would be naive to suppose that the unsustainability problems humankind is faced with could be solved with current tools and methods (models!) that were applied - or seemed to work - in the past" (Rotmans 2009).

Given the complexity of farming systems and the large number of possible adaptation options, model-based exploration tools are commonly used to supplement traditional empirical approaches (e.g. Vereijken 1997) for designing and evaluating innovative agricultural production systems. Despite some difficulties in transferring results to farmers and extension advisers (Keating and McCown 2001; Bergez et al. 2010), the usefulness of such model-based approaches has now been proven (Rossing et al. 1997).

The choice of crops and their allocation to plots is at the core of the farming system management. These decisions concentrate all the complexity involved in cropping system design and selection at the farm level because of their many involvements at different stages of the crop production processes (Nevo et al. 1994;Aubry et al. 1998b; Navarrete and Bail 2007). Cropping plan decisions are indeed crucial steps in crop production processes and have considerable effects on the annual and long-term productivity and profitability of farms. A suitable cropping plan must satisfy multiple and conflicting objectives, and take into account a large number of factors and their interactions (Nevo and Amir 1991). Many models dealing with cropping system design have been based on cropping plan selections represented through the choice of cropping plan or that of crop rotation. These two concepts, i.e. cropping plan and crop rotation, describe the cropping plan decision problem in space and time, respectively. Not all models that we reviewed were developed to support and/or imitate stakeholder decision. However, all these models allow the selection of one or several cropping plans within a given context and objectives which somehow represent a decision (not necessarily that of the farmers). To avoid confusion, we use cropping plan selection models as generic term to designate the models we reviewed. We use cropping plan decision model when the authors explicitly refer to decisionmaker behaviour (e.g. in the field of agricultural economics).

The modelling of cropping plan selection has been treated using a variety of approaches based on different objectives and handled at very different scales. More than 120 scientific references on this topic have been found. This paper reviews how cropping plan and crop rotation are formalised and incorporated into agronomic, economic and land-use models. We do not review how these models were used into research project although it is another crucial issue in model-based decision-aid. In the first section, we focus on the concept of cropping plan decision-making and clarify terminology. In the second section, we survey cropping plan selection models with a focus on arable farm and categorise the how and why of these models. In the third section, we discuss the issue of scale and the dynamic aspects of existing approaches and highlight some of their limitations.

\section{Terminology, definitions and concepts}

Before reviewing the modelling approaches dealing with cropping plan selections or any similar topics, we wish to 
clarify the terminology and definitions used in cropping plan and other related concepts. Clarification is not only useful for specifying the meanings of words but also important for realising and understanding the consequences of the use of particular concepts in cropping plan models.

\subsection{Cropping plan}

A cropping plan refers to the acreages occupied by all the different crops every year (Wijnands 1999) and their spatial distribution within a farming land (Aubry et al. 1998b). This definition includes two concepts widely used in papers on farm planning and land-use/cover (Fig. 1). The first, crop acreage, refers to the area on a farming land normally devoted to one or a group of crops every year (e.g. $x$ hectares of wheat, $y$ hectares of winter barley); the second, crop allocation, is the assignment of a particular crop to each plot in a given piece of land. Allocation can be spatially explicit (e.g. Rounsevell et al. 2003; Joannon et al. 2006) or characterised by land area attributes such as soil type (e.g. Annetts and Audsley 2002; Bachinger and Zander 2007). A cropping plan can be expressed at the farm level where most of the decisions are made (e.g. Stone et al. 1992), or at a higher level in order to address collective issues (e.g. resource uses, landscape, economy) (e.g. Rounsevell et al. 2003).

\subsection{Crop rotation}

Crop rotation is defined as the practice of growing a sequence of plant species on the same land (Bullock 1992). Crop rotation is characterised by a cycle period, while crop sequence is limited to the order of appearance of crops on the same piece of land during a fixed period (Leteinturier et al. 2006). Crop rotation is along used concept in models to represent the temporal dimension of cropping plan decisions (Heady 1948). Because the succession of crops in a given area has effects on production and consequently on cropping plan decisions, the traditional approach developed by agronomists was to derive cropping plans from the crop proportions in crop rotation. Some authors (e.g. Maxime et al. 1995; Dogliotti et al. 2003) have argued that the reproducibility of a cropping system over time is only ensured when crop choices are derived from crop rotation. Cropping plan decisions consequently require one to look back and forth in time (Fig. 2). Crop rotation as a particular crop sequence is therefore a natural starting point in designing cropping systems that are stable over time (Vereijken 1997). Crop rotation is considered as being essential for integrated farming (Stoate et al. 2001) and is in contradiction with monocropping as a sustainable solution for farms (Leteinturier et al. 2006). The concept of crop rotation is an interesting means of obtaining a succession of crops year after year on a specific piece of land. It offers the potential of attenuating the environmental impacts of agriculture while maintaining production and achievements over the years (Vandermeer et al. 1998). Crop rotations are also used for breaking weed and disease cycles, and for reducing dependence on external inputs (Bullock 1992). However, the concept of crop rotation provides very limited insight into the organisation of crops among different and heterogeneous pieces of land.

\subsection{Cropping plan decisions}

Cropping plan decisions are the main land-use decisions in farming systems and involve, at the very least, the choice of crops to be grown, their acreage and their allocation within a particular farmland (Nevo et al. 1994). These decisions mostly occur at the farm level and are consequently part of the global technical management of farm production (Aubry et al. 1998a). A cropping plan decision is the result of a decision-making process where farmers weigh up the various objectives and constraints fitted into different spatial and temporal dynamics. Because of the fact that production decisions are almost always made under uncertainty (weather, market) and that there may be several sowing seasons per year, cropping plan decision-making does not merely involve a single decision but is a continuous process occurring all throughout the year
Fig. 1 Crop acreage and crop allocation are the two interlocking elements of a cropping plan. a Crop acreage can be simplified as the crop area distribution, represented here by means of a pie chart, while $\mathbf{b}$ crop allocation calls for the explicit representation of land units, in a map for instance, or their characterisation in terms of various land attributes a
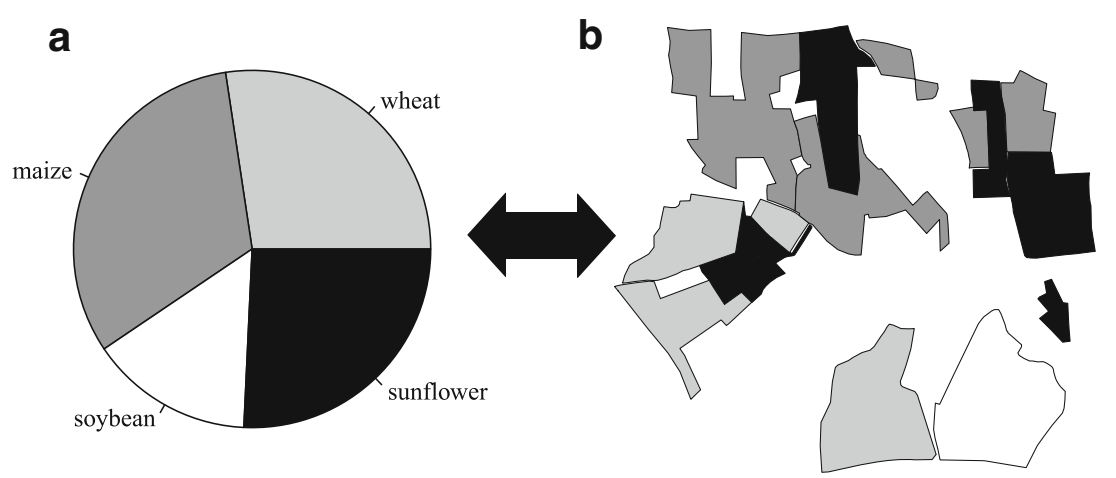


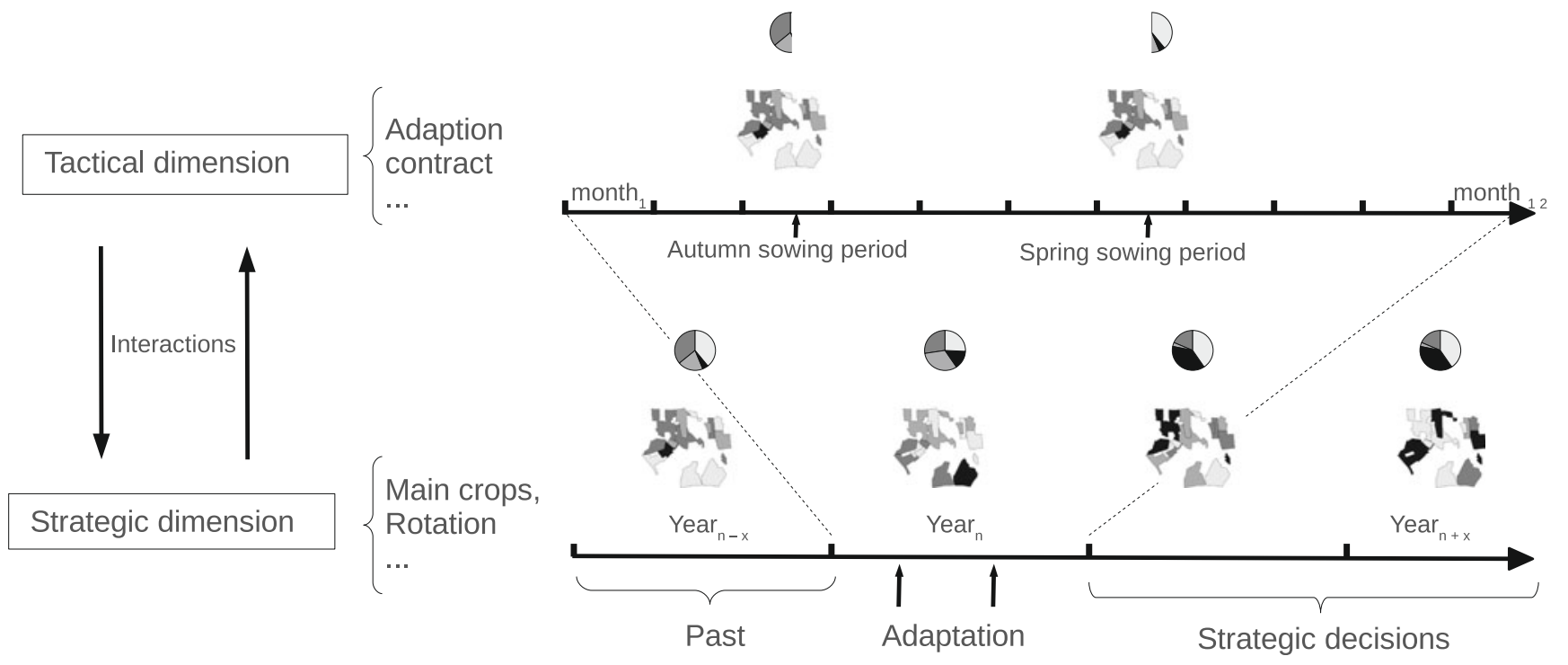

Fig. 2 Cropping plan decision-making is a combination of planned activities and dynamic decision-making for achieving a control over a dynamic system in order to produce a desired output, rather than as an

(Aubry et al. 1998b; Nuthall 2010). The decisions to choose certain crops and allocate them to certain areas within the farmland interact with one another at different levels of farm management, usually presented as two dimensions: a strategic dimension related to long-term production organisation (equipment funding, crop rotation, etc.), and a more tactical dimension linked to the possibilities of (intra-) annual adjustments in response to the changing and uncertain environment and to the organisation of work (Fig. 2).

\section{Why and how cropping plan selection have been modelled}

Given the large spectrum of consequences of cropping plan decisions at the farm and higher levels, the assessment and/ or designing of cropping plans using models are driven by many different motivations. Cropping plan selection models are mostly used to support farmers, policy maker and other stakeholders in defining strategies to allocate scarce and competing resources more efficiently, assess landscape changes, and also design policy options and anticipate their effects at different time scale horizons. Cropping plan selection models are used in research project aiming at different outcomes (Matthews 2011) and are differently used within these projects. However, these models share comparable outputs, i.e. the selection of one or more cropping plans and/or rotations. We did not reviewed cropping plan models in terms of outcomes of projects in which they were involved but rather how these models allow the selection or the design of cropping plan. We have unique resolution of choice dilemma. Cropping plan decisions are incorporated into strategic and tactical dynamic decision-making processes as interactions

summarised the various approaches as two broad issues: (1) cropping plan selection for better resource allocation and more efficient resource use, and (2) cropping plan decisions to assess large-scale changes (landscape, policy). Although this distinction is useful for presenting the existing literature, we recognise that there are in fact strong relationships between these two issues.

\subsection{Model-based exploration}

\subsubsection{Problem formalisation}

Cropping plan selection models are mostly developed by agronomists to carry out exploration studies for better resource allocation and uses. The approaches aim at designing and exploring alternative land-use systems at various scales and may support the identification of appropriate crop combinations and resource allocation options. The approaches combine the knowledge of the biophysical processes underlying agricultural production, stakeholder objectives and farm constraints. The main goal is to support the strategic thinking of farmers and other stakeholders during the design phase of farming systems. Modelling cropping plan requires a formal representation of the cropping plan selection. The boundaries of the farm system and the level of detail in the representation of the design process greatly depend upon the objectives of the study. The formalisation of cropping plan selection is mostly represented in models as a static and deterministic problem of resource allocation. The cropping plan selection problem is often addressed as the search for the best landcrop combination under some known constraints. Depend- 
ing on the objective of the study, the search for solutions is sometimes carried out at the rotational level and other times at the annual level, but in most cropping plan selection models, the decision process is represented as a single decision occurring (1) once a rotation or (2) once a year:

1. In a number of studies, cropping plan selection is directly derived from crop rotation selection used as a seminal concept in the design of cropping systems. Implementation of crop rotations into cropping plan models is often based on expert knowledge using different crop sequence representations (Table 1). Fixed recommended crop rotations (Stockle et al. 2003) or fixed computed crop rotations (Dogliotti et al. 2003; Bachinger and Zander 2007) take into account crop succession requirements. But as a consequence, there is little leeway for contextual adaptation and for choosing production plans for the following years (Kein Haneveld and Stegeman 2005). To overcome the limitations of the static rotational approach, several authors have introduced yearly flexibility by focusing on complex and flexible crop sequences/rotations (Tsai et al. 1987; Kein Haneveld and Stegeman 2005; Detlefsen and Jensen 2007; Castellazzi et al. 2008). Castellazzi et al. (2008) describe three types of flexible crop rotations: (1) cyclical with fixed rotation length, (2) cyclical with variable rotation length and (3) less structured cyclical with highly variable rotation length. Different mathematical formalisations have been used to represent such complex and flexible crop rotations in models, for example network flow problems (Tsai et al. 1987; Kein Haneveld and Stegeman 2005; Detlefsen and Jensen 2007) and Markov chains (Castellazzi et al. 2008). An interesting feature of the approaches introducing flexible crop rotations into cropping plan selection models is the given opportunity of representing annual adjustments in the cropping plan in relation to the changing context. However, clear and explicit methods of achieving this are still lacking.

2. In studies interested in cropping plan selection made on an annual basis, the crop succession requirements are either ignored (e.g. Abdulkadri and Ajibefun 1998; Leroy and Jacquin 1991) or incorporated into models as predefined factors reducing crop yields (e.g. Annetts and Audsley 2002; Garcia et al. 2005; El-Nazer and McCarl 1986). Crop yield reduction factors are either defined by experts (Garcia et al. 2005) or based on a regression analysis of historical records (El-Nazer and McCarl 1986). In such annual approaches, the cropping plan selection is seen as a static and single decision of resource allocation. None of the approaches takes into account infra-annual decisions and/or sequences of decisions in the problem formalisation. Considerations of the uncertainty of information (price, weather) and decision-makers' behaviours towards risk are indeed poorly dealt with by agronomists. These aspects are studied in much greater detail in the field of agricultural economics (see Chavas and Holt 1990; Itoh et al. 2003).

\begin{abstract}
Mono- vs multi-attribute objectives selection Cropping plans are very often selected based on a single monetary criterion, i.e. profit maximisation (e.g. Heady 1948; Leroy and Jacquin 1991; Audsley 1993; Itoh et al. 2003). Singlecriterion models mainly differ from multi-criteria ones in the way in which the cropping plan decision problem is formalised (annual or rotational) and in the set of constraints that are considered for restricting profit maximisation.
\end{abstract}

Table 1 Crop succession representations in cropping plan models based on the rotational approach

\begin{tabular}{|c|c|c|}
\hline Crop succession representation & Crop succession requirements & Authors \\
\hline Predefined by expert & & $\begin{array}{l}\text { Stockle et al. 2003; } \\
\text { Sadok et al. } 2009\end{array}$ \\
\hline \multirow[t]{4}{*}{ Rules and agronomic filter } & $\begin{array}{l}\text { Rules controlled by model's users using parameters that describe timing, } \\
\text { sequence, frequency and farm-specific constraints }\end{array}$ & Dogliotti et al. 2003 \\
\hline & Predefined forbidden crop sequences & Kein Haneveld and Stegeman 2005 \\
\hline & Timing and preceding crop supply/demand constraints, exclusion rules & Bachinger and Zander 2007 \\
\hline & Predefined allowed crop sequences (maximum 2 years) & Detlefsen and Jensen 2007 \\
\hline Indicators & $\begin{array}{l}\text { Effects of previous crop on the subsequent crop (soil structures, diseases, } \\
\text { pests, weeds and nitrogen), recurring crops and their respective } \\
\text { recommended minimal return time, crop diversity }\end{array}$ & Leteinturier et al. 2006 \\
\hline Probability of crop occurrence & Probabilities based on observed crop rotations & Castellazzi et al. 2008 \\
\hline \multirow[t]{3}{*}{ Reducing factors } & Regression analysis to estimate yield influence of preceding crop & El-Nazer and McCarl 1986 \\
\hline & $\begin{array}{l}\text { Timing and sequencing constraints, disease classes associated with } \\
\text { yield reduction penalties }\end{array}$ & Annetts and Audsley 2002 \\
\hline & Predefined yield reducing factors & Garcia et al. 2005 \\
\hline
\end{tabular}


Although it is commonly acknowledged that cropping systems must generate incomes for farmers, some authors point out the limitations of an approach that focuses exclusively on return maximisation. They argue that the decisions to do with cropping plans involve the meeting of multiple and competing objectives that have to be explicitly accounted for (Stone et al. 1992; Piech and Rehman 1993; Foltz et al. 1995; Bartolini et al. 2007). Besides, growing environmental concerns have led researchers to explicitly target objectives other than profitability (Rehman and Romero 1993; Foltz et al. 1995; Dogliotti et al. 2005; deVoil et al. 2006). Objectives that influence the selection of a cropping plan have to reflect the different goals, perspectives and values of the decision-makers. We summarise the objectives taken into account in multi-attribute cropping plan decision models into three groups (Table 2).

Apart from the objectives that determine the selection of a cropping plan, models also differ in terms of the type of constraints that restrict the selection and how these constraints are taken into account. Limiting resources that are easily quantifiable is the constraint that receives the greatest consideration in cropping plan decision models. As a typical example, irrigation water resource management is traditionally based on cropping pattern selection at the field (e.g. Tsai et al. 1987), irrigation block (e.g. Leroy and Jacquin 1991), farm (e.g. Huang et al. 1974) or regional level (e.g. Gupta et al. 2000; Kipkorir et al. 2002; Ortega Álvarez et al. 2004; Tsakiris and Spiliotis 2006; Bartolini et al. 2007). These studies focus particularly on maximising revenue from irrigation activities while respecting water availability over the seasons. Other resource availabilities such as labour (e.g. Abdulkadri and Ajibefun 1998; Itoh et al. 2003), machinery and operation timing (e.g. Annetts and Audsley 2002; Dogliotti et al. 2005) are also incorporated into models in order to constrain cropping plan decisions.

\subsubsection{Problem resolution}

Optimisation A number of techniques are used to plan crop production while accounting for known operational constraints. Mathematical programming is widely used in this area (Glen 1987). Linear programming (LP) is by far the most common optimisation procedure since Heady (1954) that has been used to solve the cropping plan decision problem (e.g. McCarl et al. 1977; Leroy and Jacquin 1991; Sarker et al. 1997). The LP model has the advantage of simplicity and of capturing the conflict between different choices (Hazell and Norton 1986). Some of the problems associated with the use of this technique include the difficulties in formulating the model (objectives and constraints) and interpreting its results (Nevo et al. 1994). The original LP framework has gradually been extended in several respects to reduce its limitations (Kennedy 1986). Simple optimisation techniques have been enriched in many ways by exploring alternative sub-optimal solutions (e.g. Abdulkadri and Ajibefun 1998), by integrating fuzzy logic techniques to take into account flexibility in decisions (e.g. Itoh et al. 2003) and qualitative factors (e.g. Nevo et al. 1994), and stochastic variables to deal with uncertain factors (e.g. Sethi et al. 2006).

Goal programming or multi-objective linear programming is another extension of LP models and is employed to solve cropping plan decisions formalised as a multiobjective decision-making problem (e.g. Piech and Rehman 1993; Sarker and Quaddus 2002; Annetts and Audsley 2002; Tsakiris and Spiliotis 2006; Bartolini et al. 2007). Depending in the study, different objectives are explicitly formulated in multi-attribute function within cropping plan models (Table 2). For instance, Annetts and Audsley (2002) developed a multi-criteria optimisation tool, the "Silsoe Whole Farm Model", for environmental farm planning

Table 2 Objectives explicitly formulated in multi-attribute cropping plan models [ $\uparrow$ maximisation, $\downarrow$ minimisation]

\begin{tabular}{|c|c|c|c|}
\hline Categories & Objectives & Indicators & Authors \\
\hline \multirow[t]{3}{*}{ Socio-economic } & Profit & $\begin{array}{l}\uparrow: \text { gross margin, annual profit, } \\
\text { income, net benefit }\end{array}$ & $\begin{array}{l}\text { Piech and Rehman 1993; Foltz et al. 1995; Mainuddin et al. 1997; } \\
\text { Gupta et al. 2000; Annetts and Audsley 2002; Tsakiris and Spiliotis 2006; } \\
\text { Dogliotti et al. 2005; Bartolini et al. 2007; Sarker and Ray 2009; } \\
\text { Louhichi et al. 2010 }\end{array}$ \\
\hline & Equipment & $\downarrow$ : investment & Gupta et al. 2000 \\
\hline & Labour & $\begin{array}{l}\downarrow: \text { total labour, } \\
\text { casual labour, cost }\end{array}$ & $\begin{array}{l}\text { Piech and Rehman 1993; Gupta et al. 2000; Dogliotti et al. 2005; } \\
\text { Bartolini et al. 2007; Sarker and Ray 2009 }\end{array}$ \\
\hline Agronomy & Irrigation & $\uparrow:$ irrigated area & Mainuddin et al. 1997; Gupta et al. 2000; Tsakiris and Spiliotis 2006 \\
\hline \multirow[t]{4}{*}{ Environment } & Energy & $\downarrow$ : calories & Gupta et al. 2000 \\
\hline & Nutrient & $\begin{array}{l}\downarrow: \text { nitrogen and phosphorus } \\
\quad \text { uses, losses }\end{array}$ & Foltz et al. 1995; Annetts and Audsley 2002; Dogliotti et al. 2005 \\
\hline & Pesticide & $\begin{array}{l}\downarrow: \text { herbicide use, losses, } \\
\text { pesticide exposures }\end{array}$ & Foltz et al. 1995; Annetts and Audsley 2002; Dogliotti et al. 2005 \\
\hline & Soil & $\begin{array}{l}\downarrow: \text { erosion, } \uparrow: \text { organic } \\
\text { matter rate of change }\end{array}$ & Dogliotti et al. 2005 \\
\hline
\end{tabular}


based on the cropping plan model of Audsley (1993). The multi-criteria optimisation tool allows us to explore whether a reduction in environmental impact is possible with a small decrease in profitability. Various multi-criteria techniques are used in cropping plan decision models to aggregate various objectives; Hayashi (2000) has written a detailed review for their application to agricultural resource management. A major difficulty of the multi-criteria approach is to elicit objectives and to attribute them weights (Sumpsi et al. 1996).

The LP framework is employed not only for annual solutions but also for solving the cropping plan problem when formalised as a crop rotation problem. Kein Haneveld and Stegeman (2005) use a standard LP model applied within a max-flow network representing the crop sequence. Pre-calculated crop sequences that are not admissible from an expert point of view are used as constraints. In a slightly different way, Detlefsen and Jensen (2007) have taken advantage of the special structure of the network representation of the rotation to use network flow modelling tools. Both these methods allow the proposal of flexible crop rotations while considering crop succession requirements over several years. Dogliotti et al. (2005) solve the crop rotation problem using mixed integer linear programming (MILP) as an interactive multiple-goal linear program. The original feature of this lies in the fact that both the complex temporal interactions of rotation and the spatial heterogeneity of soil types of the farmland are considered in the resolution of the cropping plan decision problem.

More recently, evolutionary optimisation algorithms have been used for solving multi-objective cropping plan decisions at farm level (e.g. Garcia et al. 2005), regional scale (deVoil et al. 2006), and national level (e.g. Sarker and Ray 2009). The main advantage of using genetic algorithms is to produce a set of compromise solutions along the Pareto's frontier (deVoil et al. 2006). Such algorithms are well suited for expressing solutions in a multi-objective problem context. Although the algorithms are different from LP techniques, the formalisation of the selection problem is very similar, i.e. the cropping plan is seen a static planning problem. Other mathematical programming tools have also been used to solve the cropping plan decision problem. Howitt (1995) and Louhichi et al. (2010), for instance, propose a non-linear optimisation approach based on positive mathematical programming (PMP). PMP employs both programming constraints and "positive" inferences from base-year crop allocations.

Expert systems Some authors (Stone et al. 1992; Nevo et al. 1994) have argued that using quantitative and deterministic methods alone is not enough to achieve satisfactory cropping plans due to the nature of the information that is required, as such information is often incomplete, qualitative and uncertain. Nevo et al. (1994) complement the traditional linear optimisation approach with an expert system technology that provides a solution to these limitations. The expert system approach has the advantage of providing some consistent ways of pruning the search space and reducing the number of allocation alternatives. The expert system also includes a set of adjustment rules allowing the quantification of the effect of actual production conditions on the profit from potential crop production. These rules are based on expert knowledge and are "quantified" using fuzzy logic techniques for logical conclusion or Bayesian theory to deal with uncertain processes. Stone et al. (1992) and Buick et al. (1992) tackle the cropping plan decision as a planning problem, such as that developed in the field of artificial intelligence, without using traditional optimisation techniques. One limitation of model-based expert systems is that they tend to reproduce the current situation and strong restrictions arise whenever one aims to propose alternatives and innovative cropping plans.

Evaluation procedure Another approach to the handling of the cropping plan selection problem consists in evaluating alternative cropping plans based on indicators, rather than merely selecting one solution. Multi-criteria decision-aid methods make it possible to take into account the conflicting objectives underlying the economic, social and environmental dimensions of sustainability (Sadok et al. 2009). Bachinger and Zander (2007) propose a static approach to generate, evaluate and select crop rotations adapted for organic farming. Crop rotations are selected according to exclusion criteria (i.e. thresholds for $\mathrm{N}$ balance, weed and pest infestation risks and chronological restrictions) and ranked according to economic performance. Foltz et al. (1995) use dynamic crop simulation models to obtain values for calculating indicators, and then use multi-attribute ranking to select suitable cropping plans. Using an original approach, Sadok et al. (2009) developed a qualitative multi-attribute decision model for an ex ante assessment of the sustainability of cropping systems (MASC). The MASC model integrates quantitative indicators and informal knowledge at the same level within a qualitative DEXi decision tree (Bohanec and Rajkovic 1990).

\subsection{Policy and land-use assessments}

Cropping plan choices can also be considered as part of the agricultural sector and/or regional planning, where the effect of policies on patterns of land-use is studied. In this approach, the objective is not to answer What is the best 
cropping plan?, but rather, to explore how a particular trend could evolve given the understanding of crop allocation decision-making. Trend analyses belong to the field of agricultural economics and more recently to the field of landscape ecology. The aim of this section is to outline the major trends involving cropping plan decisions in these two disciplines. These disciplines are usually interested in studying cropping plan decisions on a large scale. Our review of the existing literature will be restricted to papers that deal directly with the cropping plan decision problem.

\subsubsection{Policy assessment}

Farmers' reaction to the changing context On a large scale, the collective dynamics of farmers are generated by all individual farmer decisions mediating the impact of policy and market changes on land-uses (Winder et al. 1998). This issue has been particularly treated in agricultural economics on a large scale. The primary interest of economists has been the estimation of single-crop supply response in order to develop elasticity estimates, presumably for use in policy analysis and forecasting (Holt 1999). The econometric approach of the single-crop acreage problem has been widely used in the past based on Nerlove's model (Askari and Cummings 1977), which assumes that farmers' reactions may be represented in terms of crop acreage adjustments based on price expectations. Farmers are usually assumed to be profit maximisers and are therefore likely, at best, to fit their practices to the economical context. The consideration of crop production jointness has accelerated the development of multi-crop models (e.g. Just et al. 1983; Chambers and Just 1989; Bel Haj Hassine and Simioni 2000). The interdependences of crops are partly explained by fixed allocatable inputs such as land or water (Shumway et al. 1984). The basic acreage response framework has been extended to include risk effects due to price and production uncertainties (e.g. Chavas and Holt 1990; Baltas and Korka 2002; Itoh et al. 2003; Olarinde 2008), among other things. The original feature of this lies in the explicit incorporation of farmers' behaviours towards uncertainty and risk as a factor influencing land allocation decision-making. The econometric approaches usually do not account for the large behavioural heterogeneities across individuals.

The assumption of profit maximising behaviour is not confirmed in all studies. For instance, Vavra and Colman (2003) conclude for UK case studies that observable economic variables are unsuitable for explaining crop acreage changes at the farm level. They suggest that farmers do not necessarily share the same objectives while managing their farms. Furthermore, difference in cropping plan responses between farmers may be explained by the fact that every farm is captured at a different stage in its investment, marketing and rotation cycle. Other approaches assume that farmers do not maximise short-run profits, but rather, consider future incomes when deciding on crop allocations. Orazem and Miranowski (1994) and Thomas (2003) have incorporated agronomic considerations into their economic models. In both models, the approach consists in an economic interpretation of the crop rotation (Thomas 2003) and considers multi-annual economic constraints.

\subsubsection{Landscape ecology}

In the past 30 years, the concept of landscape has emerged in ecology: the central paradigm in landscape ecology is that the spatial structures of a landscape have an effect on the movements of individuals and the flow of matter (Burel and Baudry 2003). Cropping plan decisions, even if made at the farm level, also impact the landscape level by contributing to crop-mosaic patterning (Thenail et al. 2009). Thenail and Baudry (2004) showed that farm characteristics, especially the structure of the farm territory, have a major influence on land-use allocation on farms, which in turn influences landscape structures and the associated natural processes (Joannon et al. 2006, 2008). As a consequence, some studies aim at improving the understanding of the causes and effects of cropping plan changes to support sustainable landscape development (Mottet et al. 2006). We give here a brief overview of the different methods used for assessing landscape changes as affected by cropping plan decisions.

Landscape trend analysis Most studies in landscape ecology are aimed at describing the evolution of land-use in landscapes through statistical trends or spatial patterns without accounting for the farm level. Benoit et al. (2001) and Le Ber et al. (2006) developed data mining techniques using a land cover database, namely Ter-Uti, to describe the spatio-temporal changes in crop sequences. In a similar vein, Lazrak et al. (2010) developed a landscape description tool using hidden Markov models capable of identifying statistical time-space regularities of land-use successions at the regional level. Using a similar data-mining approach, Mignolet et al. (2007) statistically mapped homogeneous agricultural regions at the regional level. Castellazzi et al. (2007) devised statistical measures and tests for the spatial and temporal patterns of crops in order to assess the nonrandomness of spatial patterns and the temporal or spatiotemporal heterogeneity of agricultural landscapes at the regional or national level. All these statistical methods require access to a large amount of land-use data over time. Even if interactions between farming systems and landscapes are considered in most studies, scientific literature shows that farm management and farmers' cropping plan 
choices are not widely explored as a factor of the spatial and temporal dynamics of landscapes (Thenail and Baudry 2004; Thenail et al. 2009). Only a few authors (e.g. Pocewicz et al. 2008) have combined the statistical trends of landscape changes and the local practices of landowners identified through surveys.

Such statistical approaches are also used for anticipating the cropping decisions made by farmers that affect resource uses. An early decision about crop acreage for the coming year is a typical piece of information that can help to manage water at the catchment or regional level (Leenhardt et al. 2005). The prediction of crop sequences for the coming years are based on the occurrence probability of the previous crop succession (Leenhardt et al. 2005), determined using the data mining tools developed by Benoit et al. (2001) and Le Ber et al. (2006). It is therefore assumed that the observed land pattern, both in terms of space and time, may be representative of farmers' decisions, and is viewed here as a black box.

From farm to landscape Several authors (e.g. Winder et al. 1998; Rounsevell et al. 2003; Le Ber et al. 2006; Joannon et al. 2006; Louhichi et al. 2010) argue that decisions made at the farm level must be the focal point for effectively addressing issues of a larger scale. Analyses of farmers' practices are carried out to identify the local drivers of landuse changes and their underlying causes (Lambin et al. 2003; Mottet et al. 2006). Such investigations are mostly local case studies and succeed in accounting for the diversity of farmers' management choices; however, they have the disadvantage of not being generic. In the approach advocated by Rounsevell et al. (2003), land-use issues are converted into farming system questions in which farmers' decisions and their management strategies are central to the simulation of crop allocation across landscapes. The model initially developed for farm level analysis (Audsley 1993) is incorporated into a regional modelling framework. Aggregation at the regional level is carried out based on gridded soil and climate data. Similar aggregation at European level was carried out in the SEAMLESS project where geo-referenced farm type was distributed along landscapes (Louhichi et al. 2010). In such farm-oriented approaches, the models are similar to those presented in the previous section, and their original feature lies in the way in which they allow processes to be extended beyond the farm level to a much larger scale.

\section{Discussion}

4.1 Cropping plan decision-making as a dynamic process

Significant efforts have been made to integrate the many constraints that limit or influence the achievement of a plan in a specific situation. These constraints are mostly described within a static framework where economic return, and sometimes other objectives, is optimised. The few authors who combined optimisation procedures with dynamic models (Tsai et al. 1987; Foltz et al. 1995; Louhichi et al. 2010) do so by using dynamic models for the assessment of cropping plans rather than the representation of the dynamics of cropping plan decision-making processes. In such approaches, the dynamics of the mechanisms involved in the decision-making processes occurring at the farm level are not accounted for (Aubry et al. 1998b), even if they are an important part of the farmer's decision-making that must be modelled (Cox 1996; Bacon et al. 2002; Garcia et al. 2005). Cropping plan decisions are not treated by agronomists as a continuous process incorporated into a succession of other planned and adaptive decisions made at annual and longterm horizons. Only few authors explicitly formalised into details the processes of decision-making by farmers (e.g. Aubry et al. 1998b; Navarrete and Bail 2007). In approaches developed in agricultural economics, more interest is paid to the description of the dynamics of the decisions, but farmers' decision-making processes are not made explicit (e.g. Thomas 2003).

One important challenge in modelling farming system production does not only rely on making of more accurate biophysical models but also on being more relevant to their application in real situations of decision-making (Keating and McCown 2001; Carberry et al. 2002). Part of the technical solution could be the use of coupled and distinct management and biophysical simulation models (Le Gal et al. 2009; Martin-Clouaire and Rellier 2009). The introduction of management models allows a more appropriate analysis of the evolutions of farmers' practices arising from contextual changes than that provided by stand-alone biophysical models (Bergez et al. 2010); such management models also improve farmers' managerial support (Cox 1996; Attonaty et al. 1999). The development of a cropping plan management model will require the study of the decision-making process dynamic of farmers and a better understanding of the objectives that drive their decisions (Sumpsi et al. 1996; Ohlmer et al. 1998).

\subsection{Uncertainty and risk management}

While risk and uncertainty are clearly important determinants of cropping patterns (Chavas and Holt 1990), they are largely ignored in cropping plan decision models, particularly when they are formulated as an LP problem (e.g. Itoh et al. 2003; Sethi et al. 2006). In agricultural economics, risks are mostly taken into account by using stochastic variables (e.g. Itoh et al. 2003; Baltas and Korka 2002; Olarinde 2008) to better predict the non-deterministic aspect of decision-makers' behaviours. The uncertainty of information used in the 
decision problem is defined as the probability of occurrence. The probability is often kept static whatever the decisionmaker's knowledge regarding the evolutionary dynamics of the constraints. In most decision-making problems, farmers have the opportunity to make sequential decisions to adjust their choices as a season progresses and more information becomes available (Dorward 1999; Nuthall 2010). The risk is therefore not only a matter of probabilities or stochasticity but also a matter of tactical responses (Dorward 1999) to the so-called embedded risk (Hardaker et al. 1991). Farmer attitudes to risk, differing views on future prices and profitability, and the effect of time lags on decisions have also to be taken into account in a cropping plan decision model (Rounsevell et al. 2003).

An important aspect that is not covered in the cropping plan decision models developed for design purposes is the consideration of possible adaptations to changing circumstances (Dorward 1999). The majority of the models developed by agronomists propose normative and prescriptive solutions based on a static description of the decision problem (e.g. Sarker and Ray 2009). Although agronomists strive to develop models that strengthen the strategic thinking of farmers (e.g. Dogliotti et al. 2004), they implicitly base their solutions on the assumption that the world is stable and somehow predictable. If we consider this in a context of continuous and barely predictable change, there are no single optimal solutions, but certainly a trade-off between short-term optimisation and a long-term adaptive response to unpredictable changes (Rammel and van den Bergh 2003). Such normative modelling approaches are very useful for exploring alternative solutions (Rossing et al. 1997; Dogliotti et al. 2005) but are of little use for supporting the decision makers because of the decision problem formulation (Cox 1996; Ohlmer et al. 1998; Mackenzie et al. 2006). Furthermore, normative and prescriptive modelling approaches are useful to support decision-making when used in decision-making situations that are well structured (Mackenzie et al. 2006) which is not the case for most of farmer's decision-making problems (Ohlmer et al. 1998; McCown 2002; Mackenzie et al. 2006). Helping farmers to improve their adaptive capacity appears to be more relevant for strengthening the strategic thinking of farmers than the prescription of turnkey solutions (Darnhofer et al. 2008). Innovative cropping plan decision models could help to develop farmer's ability to address changing and uncertain conditions if they are formalised as an adaptive and continuous process (Smit et al. 1999).

\subsection{Spatial representation and scale issues}

The extent of spatial detail used to represent the cropping plan should be determined by the objectives of the study and the appropriate scale for presenting the results (Leenhardt et al. 2010). Crop allocation processes are treated at various scales involving different spatial representations of land heterogeneity for the systems under investigation. In most of the modelling approaches, the cropping plan is not spatially represented and is summarised as simple crop acreage distributions across various land types. At the farm level, the heterogeneity of a farm territory is generally described using soil type as the sole criterion. Soil types are linked to crop-specific production functions or models in order to differentiate between them. Some authors, focusing on resource uses, introduce other variables, for instance water availability, to distinguish irrigated from non-irrigated lands (Leroy and Jacquin 1991). The main advantages of the acreage approach lie in the genericity offered by the models and the ease of use in mathematical models. A few authors (Stone et al. 1992; Joannon et al. 2006; Nevo et al. 1994; Garcia et al. 2005; Dogliotti et al. 2005) do not describe farming land as continuous lands but have introduced discrete management units. In such cases, management units are usually reduced to the plot unit, even if such units are in reality much more complex (Aubry 2000; Papy 2001; Navarrete and Bail 2007). Spatial constraints related to the farming land (e.g. field accessibility, spatial distribution) are hardly taken into account (Joannon et al. 2006; Navarrete and Bail 2007) despite their effects on the organisation of work from season to season, as shown by Morlon and Trouche (2005).

Many methods set aside the farm level and directly address the crop allocation problem on a larger scale. In some regional studies, the population of farmers is viewed as a single unit and not as a diverse group of actors spread across the landscape (Winder et al. 1998). The farming land under investigation is mostly assumed to be a continuous aggregate of homogeneous pieces of land and is somehow likened to one big farm. Other approaches, which are farm-oriented, are grounded on the assumption that the region can be represented by the proportional sum of different farm types (e.g. Rounsevell et al. 2003; Bartolini et al. 2007). In such approaches, the crop allocation processes are usually very simplified, and the distinction between land units is based on soil type and water accessibility. Much of the spatial variation is obscured when land evaluation units are aggregated to form large units (Hijmans and van Ittersum 1996), despite the fact that farm structures do actually have a major influence on land-use allocation (Thenail and Baudry 2004; Morlon and Trouche 2005; Thenail et al. 2009). As a consequence, in order to improve the understanding of the processes and patterns taking place at different levels of analysis, there is a need for an improved linkage of micro-studies, which explain local processes but cannot 
easily be extended to larger scales, and macro-studies, which give global trends but do not guarantee any causality between processes (Verburg and Veldkamp 2001). A better knowledge about the temporal dimension of farmers' cropping plan decision-making would also be a key step for helping managers of rural spaces in designing appropriate policies for local environmental issues. Many of these environmental issues are indeed strongly impacted by the landscape spatial organisation, for instance risk of spatial dissemination between GM and non-GM maize at the level of supply basins (Le Bail et al. 2010), risk of soil erosive run-off at the catchment level (Joannon et al. 2006), and risk of phoma stem canker dissemination on oilseed rape at the landscape level (LôPelzer et al. 2010). In order to favourably orientate the crop spatial organisation at the landscape level, it would be necessary to coordinate individual farmer cropping plan decisions or at best, to chose concerted cropping plans at the landscape level. To do so, one needs to know exactly when farmers make their decisions and until when the planned decisions can be adjusted.

\section{Conclusion}

To take the decision support modelling approaches a step further, the formalisation of the cropping plan decisionmaking problem should be carried out within an integrative modelling framework that takes into account the various levels of the temporal and spatial dimensions of the decision-making problem rather than formulated as a static and deterministic procedure. Innovative models tackling the issue of cropping plan decisions require new modelling paradigm based on the simulation of the decision-making processes rather than on single normative approaches. The modelling of cropping plan decision-making processes occurring at the farm level needs to explicitly consider interactions between a set of constraints of very different natures represented in their different time scale dynamics. To achieve this, there is a need to better understand and formalise the dynamics of the processes of cropping plan decision-making by farmers and the determinants of their decisions including risk aversion, for instance price and weather conditions. The use of integrated biophysical and decision models is now recognised as an advance in farming system design and could be an interesting solution to structuring all the elements that constitute the complexity of the cropping plan decision-making problem. Rethinking the cropping plan decisions as a decision-making process at farm level is a means of reconciling the flexibility to increase the adaptive capacities of crop choices and the need to maintain cropping system robustness in farm production over time.
Acknowledgements This research work was funded by INRA, Arvalis-institut du végétal and CETIOM through the establishment of the UMTeau. UMTeau is a joint research and development unit working on tools and methods for a better agricultural quantitative water management: from the irrigation block up to an irrigation collective area. We sincerely thank Sze Mei Ringeval for checking and correcting the English language.

\section{References}

Abdulkadri AO, Ajibefun IA (1998) Developing alternative farm plans for cropping system decision making. Agric Syst 56 (4):431-442

Annetts J, Audsley E (2002) Multiple objective linear programming for environmental farm planning. J Oper Res Soc 53(9):933-943

Askari H, Cummings JT (1977) Estimating agricultural supply response with the nerlove model: a survey. Int Econ Rev 18 (2):257-292

Assessment ME (2005) Ecosystems and human well-being: general synthesis. Island Press, Washington, DC, 137

Attonaty J-M, Chatelin M-H, Garcia F (1999) Interactive simulation modeling in farm decision-making. Comput Electron Agric 22 (2-3): $157-170$

Aubry C (2000) Une modélisation de la gestion de production dans 1'exploitation agricole. Rev Fr gest 129:32-46

Aubry C, Biarnes A, Maxime F, Papy F (1998a) Modélisation de l'organisation technique de la production dans l'exploitation agricole: la constitution de systèmes de culture. Etudes \& Recherches sur les Systèmes Agraires et le Développement 31:25-43

Aubry C, Papy F, Capillon A (1998b) Modelling decision-making processes for annual crop management. Agric Syst 56(1):45-65

Audsley E (1993) Labour, machinery and cropping planning. Wageningen, The Netherlands, pp 83-88

Bachinger J, Zander P (2007) ROTOR, a tool for generating and evaluating crop rotations for organic farming systems. Eur $\mathrm{J}$ Agron 26(2):130-143

Bacon PJ, Cain JD, Howard DC (2002) Belief network models of land manager decisions and land use change. J Environ Manage 65 (1): $1-23$

Baltas NC, Korka O (2002) Modelling farmers' land use decisions. Appl Econ Lett 9(7):453-457

Bartolini F, Bazzani G, Gallerani V, Raggi M, Viaggi D (2007) The impact of water and agriculture policy scenarios on irrigated farming systems in Italy: an analysis based on farm level multiattribute linear programming models. Agric Syst 93(1-3):90-114

Bel Haj Hassine N, Simioni M (2000) Estimation of two-stage models of multicrop production: with an application to irrigated water allocation in Tunisian agriculture. Région et développement, $121-141$

Benoit M, Le Ber F, Mari JF (2001) Recherche des successions de cultures et de leurs évolutions: analyse par HMM des données Ter-Uti en Lorraine. La statistique agricole 31:23-30

Bergez J, Colbach N, Crespo O, Garcia F, Jeuffroy M, Justes E, Loyce C, Munier-Jolain N, Sadok W (2010) Designing crop management systems by simulation. Eur J Agron 32(1):3-9

Bohanec M, Rajkovic V (1990) DEX: an expert system shell for decision support. Sistemica 1(1):145-157

Buick RD, Stone ND, Scheckler RK, Roach JW (1992) CROPS: a whole-farm crop rotation planning system to implement sustainable agriculture. AI Appl 6(3):29-50

Bullock DG (1992) Crop rotation. Crit Rev Plant Sci 11(4):309-326

Burel F, Baudry J (2003) Landscape ecology: concepts, methods, and applications. Science Publisher, Hampshire 
Carberry PS, Hochman Z, McCown RL, Dalgliesh NP, Foale MA, Poulton PL, Hargreaves JNG, Hargreaves DMG, Cawthray S, Hillcoat N, Robertson MJ (2002) The FARMSCAPE approach to decision support: farmers', advisers', researchers' monitoring, simulation, communication and performance evaluation. Agric Syst 74(1):141-177

Castellazzi M, Perry J, Colbach N, Monod H, Adamczyk K, Viaud V, Conrad K (2007) New measures and tests of temporal and spatial pattern of crops in agricultural landscapes. Agric Ecosyst Environ 118(1-4):339-349

Castellazzi M, Wood G, Burgess P, Morris J, Conrad K, Perry J (2008) A systematic representation of crop rotations. Agric Syst 97(12):26-33

Chambers RG, Just RE (1989) Estimating multioutput technologies. Am J Agric Econ 71(4):980-995

Chavas JP, Holt MT (1990) Acreage decisions under risk: the case of corn and soybeans. Am J Agric Econ 72(3):548-555

Cox PG (1996) Some issues in the design of agricultural decision support systems. Agric Syst 52(2-3):355-381

Dalgaard T, Hutchings NJ, Porter JR (2003) Agroecology, scaling and interdisciplinarity. Agric Ecosyst Environ 100(1):39-51

Darnhofer I, Bellon S, Dedieu B et al. (2008) Adaptive farming systems - a position paper. In: 8th European IFSA Symposium. Clermont-Ferrand (France), pp. 339-351

Detlefsen NK, Jensen AL (2007) Modelling optimal crop sequences using network flows. Agric Syst 94(2):566-572

deVoil P, Rossing WAH, Hammer GL (2006) Exploring profitsustainability trade-offs in cropping systems using evolutionary algorithms. Environ Modell Softw 21(9):1368-1374

Dogliotti S, Rossing WAH, van Ittersum MK (2003) ROTAT, a tool for systematically generating crop rotations. Eur J Agron 19 (2):239-250

Dogliotti S, Rossing WAH, van Ittersum MK (2004) Systematic design and evaluation of crop rotations enhancing soil conservation, soil fertility and farm income: a case study for vegetable farms in South Uruguay. Agric Syst 80(3):277-302

Dogliotti S, Ittersum MV, Rossing W (2005) A method for exploring sustainable development options at farm scale: a case study for vegetable farms in South Uruguay. Agric Syst 86(1):29-51

Dorward A (1999) Modelling embedded risk in peasant agriculture: methodological insights from northern Malawi. Agric Econ 21 (2):191-203

El-Nazer T, McCarl BA (1986) The choice of crop rotation: a modelling approach and case study. Am J Agric Econ 68(1):127136

European Parliament Council (2006) Registration, Evaluation, Authorisation and Restriction of Chemicals (REACH)

Foltz J, Lee J, Martin M, Preckel P (1995) Multiattribute assessment of alternative cropping systems. Am J Agric Econ 77(2):408-420

Garcia F, Guerrin F, Martin-Clouaire R et al. (2005) The human side of agricultural production management: the missing focus in simulation approaches

Glen J (1987) Mathematical-models in farm-planning: a survey. Oper Res 35(5):641-666

Griffon M (1999) The doubly green revolution: models and realities. Cah Agric 8:259-268

Gupta AP, Harboe R, Tabucanon MT (2000) Fuzzy multiple-criteria decision making for crop area planning in Narmada river basin. Agric Syst 63(1):1-18

Hardaker JB, Pandey S, Patten LH (1991) Farm planning under uncertainty: a review of alternative programming models

Hayashi K (2000) Multicriteria analysis for agricultural resource management: a critical survey and future perspectives. Eur J Oper Res 122(2):486-500

Hazell PBR, Norton RD (1986) Mathematical programming for economic analysis in agriculture. Macmillan
Heady EO (1948) The economics of rotations with farm and production policy applications. J Farm Econ 30(4):645-664

Heady EO (1954) Simplified presentation and logical aspects of linear programming technique. J Farm Econ 36(5):1035-1048

Hijmans R, van Ittersum M (1996) Aggregation of spatial units in linear programming models to explore land use options. Neth $\mathrm{J}$ Agric Sci 44(2):145-162

Holt MT (1999) A linear approximate acreage allocation model. J Agric Resour Econ 24(2):383-397

Howitt RE (1995) Positive mathematical programming. Am J Agric Econ 77(2):329-342

Huang W, Liang T, Wu I (1974) Optimizing water utilization through multiple crops scheduling. In: Annual Meeting of the American Society of Agricultural Engineers. Oklahoma, p. 26

Itoh T, Ishii H, Nanseki T (2003) A model of crop planning under uncertainty in agricultural management. Int J Prod Econ 81$82: 555-558$

Joannon A, Souchère V, Martin P, Papy F (2006) Reducing runoff by managing crop location at the catchment level, considering agronomic constraints at farm level. Land Degrad Dev 17 (5):467-478

Joannon A, Bro E, Thenail C, Baudry J (2008) Crop patterns and habitat preferences of the grey partridge farmland bird. Agron Sustainable Dev 28(3):379-387

Just RE, Zilberman D, Hochman E (1983) Estimation of multicrop production functions. Am J Agric Econ 65(4):770-780

Keating BA, McCown RL (2001) Advances in farming systems analysis and intervention. Agric Syst 70(2-3):555-579

Kein Haneveld WK, Stegeman AW (2005) Crop succession requirements in agricultural production planning. Eur J Oper Res 166 (2):406-429

Kennedy JOS (1986) Dynamic programming: applications to agriculture and natural resources. Elsevier Science Pub. Co, New York

Kipkorir EC, Sahli A, Raes D (2002) MIOS: a decision tool for determination of optimal irrigated cropping pattern of a multicrop system under water scarcity constraints. Irrigat Drain 51(2):155166

Lambin EF, Geist HJ, Lepers E (2003) Dynamics of land-use and "land cover" change in tropical regions "land use". Annu Rev Environ Resour 28(1):205-241

Lazrak EG, Mari JF, Benoit M (2010) Landscape regularity modelling for environmental challenges in agriculture. Landscape Ecol 25 (2): $1-15$

Le Bail M, Lecroart B, Gauffreteau A, Angevin F, Messean A (2010) Effect of the structural variables of landscapes on the risks of spatial dissemination between GM and non-GM maize. Eur $\mathrm{J}$ Agron 33(1):12-23

Le Ber F, Benoit M, Schott C, Mari J-F, Mignolet C (2006) Studying crop sequences with CarrotAge, a HMM-based data mining software. Ecol Modell 191(1):170-185

Le Gal P-Y, Merot A, Moulin C-H, Navarrete M, Wery J (2009) A modelling framework to support farmers in designing agricultural production systems. Environ Modell Softw 25(2):258-268

Leenhardt D, Cernesson F, Mari JF et al. (2005) Anticiper l'assolement pour mieux gérer les ressources en eau: comment valoriser les données d'occupation du sol? Ingénieries - E A T, 13-22

Leenhardt D, Angevin F, Biarnes A, Colbach N, Mignolet C (2010) Describing and locating cropping systems on a regional scale. A review. Agron Sustainable Dev 30(1):131-138

Leroy P, Jacquin C (1991) LORA: a decision support system for the choice of crops on the irrigable area of a farm. Bruges, p. 11

Leteinturier B, Herman J, Longueville FD, Quintin L, Oger R (2006) Adaptation of a crop sequence indicator based on a land parcel management system. Agric Ecosyst Environ 112(4):324-334

Lô-Pelzer E, Bousset L, Jeuffroy M, Salam M, Pinochet X, Boillot M, Aubertot J (2010) SIPPOM-WOSR: a simulator for integrated 
pathogen population management of phoma stem canker on winter oilseed rape: I. Description of the model. Field Crops Res 118(1):73-81

Louhichi K, Kanellopoulos A, Janssen S, Flichman G, Blanco M, Hengsdijk H, Heckelei T, Berentsen P, Lansink AO, van Ittersum M (2010) FSSIM, a bio-economic farm model for simulating the response of EU farming systems to agricultural and environmental policies. Agric Syst 103(8):585-597

Mackenzie A, Pidd M, Rooksby J, Sommerville I, Warren I, Westcombe M (2006) Wisdom, decision support and paradigms of decision making. Eur J Oper Res 170(1):156-171

Mainuddin M, Das Gupta A, Raj Onta P (1997) Optimal crop planning model for an existing groundwater irrigation project in Thailand. Agric Water Manage 33(1):43-62

Martin-Clouaire R, Rellier J-P (2009) Modelling and simulating work practices in agriculture. Int J Metadata Semant Ontol 4(1/2):42-53

Matthews KB et al. (2011) Raising the bar? - The challenges of evaluating the outcomes of environmental modelling and software. Environmental Modelling \& Software 26(3):247-257. Available at: http://www.sciencedirect.com/science/article/ B6VHC-4YXMP6Y-2/2/2bc0ee0e670a4218b1e3a6768d04cc68 [Accessed February 24, 2011].

Maxime F, Mollet JM, Papy F (1995) Aide au raisonnement de l'assolement en grande culture. Cah Agric 4:351-362

McCarl BA, Candler WV, Doster DH, Robbins PR (1977) Experiences with farmer oriented linear programming for crop planning. Can J Agr Econ 25(1):17-30

McCown RL (2002) Changing systems for supporting farmers' decisions: problems, paradigms, and prospects. Agric Syst 74 (1): 179-220

Meynard JM, Doré T, Habib R (2001) L'évaluation et la conception de systèmes de culture pour une agriculture durable. Comptes rendus de l'Académie d'agriculture de France 87(4):223-236

Mignolet C, Schott C, Benoit M (2007) Spatial dynamics of farming practices in the Seine Basin: methods for agronomic approaches on a regional scale. Sci Total Environ 375(1-3):13-32

Morlon P, Trouche G (2005) La logistique dans les exploitations de « grande culture»: nouveaux enjeux. 1-L'organisation spatiale des chantiers, une question dépassée en grande culture. Cah Agric 14 (2):233-239

Mottet A, Ladet S, Coqué N, Gibon A (2006) Agricultural land-use change and its drivers in mountain landscapes: a case study in the pyrenees. Agric Ecosyst Environ 114(2-4):296-310

Navarrete M, Bail ML (2007) SALADPLAN: a model of the decisionmaking process in lettuce and endive cropping. Agron Sustainable Dev 27(3):209-221

Nevo A, Amir I (1991) CROPLOT - an expert system for determining the suitability of crops to plots. Agric Syst 37(3):225-241

Nevo A, Oad R, Podmore TH (1994) An integrated expert system for optimal crop planning. Agric Syst 45(1):73-92

Nuthall P (2010) Farm business management: the human factor. CAB International

Ohlmer B, Olson K, Brehmer B (1998) Understanding farmers' decision making processes and improving managerial assistance. Agric Econ 18(3):273-290

Olarinde L (2008) Analysing optimum and alternative farm plans for risk averse grain crop farmers in Kaduna state, Northern, Nigeria. World J Agric Sci 4(1):28-35

Orazem PF, Miranowski JA (1994) A dynamic model of acreage allocation with general and crop-specific soil capital. Am J Agric Econ 76(3):385-395

Ortega Álvarez J, Juan Valero J, Tarjuelo Martìn-Benito J, López Mata E (2004) MOPECO: an economic optimization model for irrigation water management. Irrig Sci 23(2):61-75

Pachauri RK, Reisinger A (2007) Climate change 2007: synthesis report. IPCC, Geneva
Papy F (2001) Interdépendence des systèmes de culture dans l'exploitation, cirad, inr Edition. Repères. pp. 51-74

Piech B, Rehman T (1993) Application of multiple criteria decision making methods to farm planning: a case study. Agric Syst 41 (3):305-319

Pocewicz A, Nielsen-Pincus M, Goldberg CS, Johnson MH, Morgan P, Force JE, Waits LP, Vierling L (2008) Predicting land use change: comparison of models based on landowner surveys and historical land cover trends. Landscape Ecol 23 (2): $195-210$

Rammel C, van den Bergh JC (2003) Evolutionary policies for sustainable development: adaptive flexibility and risk minimising. Ecol Econ 47(2-3):121-133

Rehman T, Romero C (1993) The application of the MCDM paradigm to the management of agricultural systems: Some basic considerations. Agric Syst 41(3):239-255

Rossing WAH, Meynard JM, van Ittersum MK (1997) Model-based explorations to support development of sustainable farming systems: case studies from France and the Netherlands. Eur J Agron 7(1-3):271-283

Rotmans J (2009) Two decades of integrated assessment tools: a promising way forward. In: Integrated assessment of agriculture and sustainable development (AgSAP). Egmond aan Zee, The Netherlands, pp 8-10

Rounsevell MDA, Annetts JE, Audsley E, Mayr T, Reginster I (2003) Modelling the spatial distribution of agricultural land use at the regional scale. Agric Ecosyst Environ 95(2-3):465-479

Sadok W, Angevin F, Bergez J-E, Bockstaller C, Colomb B, Guichard L, Reau R, Messéan A, Doré T (2009) MASC, a qualitative multi-attribute decision model for ex ante assessment of the sustainability of cropping systems. Agron Sustainable Dev 29 (3):447-461

Sarker RA, Quaddus MA (2002) Modelling a nationwide crop planning problem using a multiple criteria decision making tool. Comput Ind Eng 42(2-4):541-553

Sarker R, Ray T (2009) An improved evolutionary algorithm for solving multi-objective crop planning models. Comput Electron Agric 68(2):191-199

Sarker RA, Talukdar S, Haque AFMA (1997) Determination of optimum crop mix for crop cultivation in Bangladesh. Appl Math Model 21(10):621-632

Sethi LN, Panda SN, Nayak MK (2006) Optimal crop planning and water resources allocation in a coastal groundwater basin, Orissa, India. Agric Water Manage 83(3):209-220

Shumway CR, Pope RD, Nash EK (1984) Allocatable fixed inputs and jointness in agricultural production: implications for economic modeling. Am J Agric Econ 66(1):72-78

Smit B, Burton I, Klein RJT, Street R (1999) The science of adaptation: a framework for assessment. Mitig Adapt Strateg Glob Change 4(3):199-213

Stoate C, Boatman ND, Borralho RJ, Carvalho CR, Snoo GR, Eden P (2001) Ecological impacts of arable intensification in Europe. J Environ Manage 63(4):337-365

Stockle CO, Donatelli M, Nelson R (2003) CropSyst, a cropping systems simulation model. Eur J Agron 18(3-4):289-307

Stone ND, Buick RD, Roach JW, Scheckler RK, Rupani R (1992) The planning problem in agriculture: farm-level crop rotation planning as an example. AI Appl 6(1):59-75

Sumpsi J, Amador F, Romero C (1996) On farmers' objectives: a multi-criteria approach. Eur J Oper Res 96(1):64-71

Thenail C, Baudry J (2004) Variation of farm spatial land use pattern according to the structure of the hedgerow network (bocage) landscape: a case study in northeast Brittany. Agric Ecosyst Environ 101(1):53-72

Thenail C, Joannon A, Capitaine $M$, Souchère $V$, Mignolet $C$, Schermann N, Di Pietro F, Pons Y, Gaucherel C, Viaud V, 
Others (2009) The contribution of crop-rotation organization in farms to crop-mosaic patterning at local landscape scales. Agric Ecosyst Environ 131(3-4):207-219

Thomas A (2003) A dynamic model of on-farm integrated nitrogen management. Eur Rev Agric Econ 30(4):439-460

Tsai YJ, Jones JW, Mishoe JW (1987) Optimizing multiple cropping systems: a systems approach. Trans ASAE 30(6):1554-1561

Tsakiris G, Spiliotis M (2006) Cropping pattern planning under water supply from multiple sources. Irrig Drain Syst 20(1):57-68

Vandermeer J, van Noordwijk M, Anderson J, Ong C, Perfecto I (1998) Global change and multi-species agroecosystems: concepts and issues. Agric Ecosyst Environ 67(1):1-22

Vavra P, Colman D (2003) The analysis of UK crop allocation at the farm level: implications for supply response analysis. Agric Syst 76(2):697-713
Verburg PH, Veldkamp A (2001) The role of spatially explicit models in land-use change research: a case study for cropping patterns in China. Agric Ecosyst Environ 85(13): $177-190$

Vereijken P (1997) A methodical way of prototyping integrated and ecological arable farming systems (I/EAFS) in interaction with pilot farms. Eur J Agron 7(1-3):235-250

Wijnands E (1999) Crop rotation in organic farming: theory and practice. In: Designing and testing crop rotations for organic farming. Proceedings from an international workshop. Danish Research Centre for Organic Farming, pp. 21-35

Winder N, Jeffrey P, Lemon M (1998) Simulation of crop choice dynamics: an application of nested Master-Equation models. Etudes et Recherches sur les Systemes Agraire et le Developpment Vol 31, pp. 175-189.Vol. 31. Quae, pp. 175-189 